\author{
Anđelka Pejović ${ }^{1}$ \\ Univerzitet u Beogradu \\ Srbija
}

\title{
O REČNICIMA KOJI UKLJUČUJU ŠPANSKI I SRPSKI JEZIK ${ }^{2}$
}

\begin{abstract}
Rezime
U radu dajemo pregled rečnika koji sadrže španski i srpski jezik, a koji su objavljeni na teritoriji bivše Jugoslavije i u Republici Srbiji, zaključno sa 2019. godinom. Prvi rečnici koji uključuju pomenute jezike datiraju iz 60-ih godina XX veka, a od 90-tih godina, u Republici Srbiji objavljeno je još 20 dvojezičnika i 11 višejezičnih rečnika. Solidan broj specijalizovanih, pre svega terminoloških, rečnika u odnosu na opšte mogao bi da ukazuje na veću potrebu za upravo ovom vrstom leksikografske građe, dok preštampavanje rečnika opšte namene može da se tumači kao indikator potrebe za rečnicima koji obuhvataju opšti leksički fond. Odsustvo obimnijih rečnika opšte namene moglo bi da se objasni i time da, s jedne strane, njihova izrada zahteva, osim odgovarajućih kompetencija, veoma mnogo vremena, napora i adekvatnu tehničku podršku, pri čemu leksikografski rad nije adekvatno vrednovan, a s druge time da prevodioci imaju visok nivo poznavanja kako jezika s kojeg prevode tako i maternjeg jezika, da se služe kvalitetnim i pouzdanim jednojezičnim rečnicima.

Ključne reči: leksikografija, rečnici, dvojezični rečnici, višejezični rečnici, španski jezik, srpski jezik.

\footnotetext{
${ }^{1}$ andjelka.pejovic@fil.bg.ac.rs

${ }^{2}$ Rad je urađen u okviru istraživačkog projekta Dinamika struktura savremenog srpskog jezika (projekat broj 178014), koji finansira Ministarstvo prosvete, nauke i tehnološkog razvoja Republike Srbije.
} 


\section{Uvod}

O hispanistici u Srbiji najiscrpnije je pisao Soldatić (2011), koji je njenom razvoju doprineo praktično od osnivanja studijske grupe Španski jezik i književnost na Filološkom fakultetu 1971. godine. Soldatić (2011: 36-37) primećuje „da u Srbiji još uvek nemamo ozbiljan rečnik špansko-srpskog i srpsko-španskog jezika“. U jednom od ranijih radova, u kome govorimo o aktuelnom stanju i perspektivama španskog jezika u Srbiji (Pejović 2013), i mi ukazujemo na leksikografske domete kao na svojevrsnu „slabu tačku“ srpske hispanistike. To ne znači da govorimo negativno o postojećim špansko-srpskim / srpsko-španskim rečnicima, već samo iznosimo da je leksikografski domen u srpskoj hispanistici manje razvijen od ostalih, kao što su, na primer, naučnoistraživačka ili prevodilačka delatnost. Zbog toga su predmet ovoga rada upravo postojeći špansko-srpski / srpsko-španski rečnici, a cilj je da ustanovimo koliko je i koji su tipovi rečnika do sada objavljeni kod nas, te da o tome informišemo potencijalne korisnike, kako bi znali koje rečnike imaju na raspolaganju.

Naša namera ovom prilikom nije da ulazimo u kvalitet pojedinačnih rečnika, i to iz najmanje dva razloga: najpre, kvalitet rečnika nastalih pre više desetina godina „nije nimalo pravedno meriti današnjim merilima, jer iz perspektive 21. veka oni neizbežno ostavljaju nepovoljniji utisak nego onda kada su prvi put objavljeni“ (Kostić-Tomović 2017: 232); a zatim, i kada bi se uspostavili parametri za određivanje kvaliteta rečnika, oni i dalje ne bi bili garancija kvalitetne upotrebe rečnika, budući da i sami korisnici treba da poseduju određena znanja i kompetencije, kako bi mogli da što adekvatnije koriste leksikografske produkte. Prema tome, ono što bi leksikografi i specijalisti mogli da ocene kao dobar ili manje dobar rečnik, različiti korisnici bi mogli da procene drugačije, u zavisnosti od sopstvenih iskustava, uslovljenih kako potrebama tako i postojećim znanjima i kompetencijama. Ipak, u radu ćemo ukazati na eventualne propuste i omaške koje smo uočili, isključivo u svrhu revidiranja rečnika.

Korpus za ovo istraživanje čine rečnici koji uključuju španski i srpski jezik, objavljeni na teritoriji bivše Jugoslavije i u Republici Srbiji, zaključno sa 2019. godinom, a pretragu smo vršili u COBISS-u. Budući da u postojećim katalozima ne nalazimo kompletne informacije o makro- i mikrostrukturi rečnika, na primer podatke vezane za broj odrednica, uvodne napomene, način ustrojstva i slično, pregledali smo svaki od rečnika posebno. U korpus smo uvrstili pre svega dvojezične rečnike 
pomenutih jezika, jer polazimo od pretpostavke da su izrađeni ciljano, upravo za španski i srpski jezik, a kratko se osvrćemo i na višejezičnike koji uključuju ove jezike. Na kraju rada, u vidu Dodatka, dostupni su bibliografski podaci o jednim i drugim rečnicima.

\section{Ukratko o rečnicima}

Da bismo razumeli koje vrste špansko-srpskih / srpsko-španskih rečnika postoje kod nas i kojoj vrsti korisnika oni mogu biti od koristi, potrebno je da predstavimo tipologiju rečnika.

Porto Dapena (2002: 42-76) razlikuje, najpre, jezičke od nejezičkih rečnika ili enciklopedija, a zatim jezičke rečnike deli, u najkraćim crtama, prema vremenskoj perspektivi (na sinhronijske i dijahronijske), prema broju jezika (jednojezični, dvojezični i višejezični), prema obimu obrađene leksike (opšti i posebni ili restriktivni rečnici), zatim prema jezičkom planu (rečnici jezika, norme i govora, koji odgovaraju tripartitnoj podeli rumunskog lingviste Košerijua jezik-norma-govor), prema mikrostrukturi (deskriptivni i nedeskriptivni rečnici), prema načinu ustrojstva (alfabetski, ideološki, prema etimološkim gnezdima, statistički, itd.) i prema mediju (štampani i elektronski rečnici).

Šipka (2006: 160-164) definiše kriterijume za tipologiju rečnika polazeći od građe, sastavljača i korisnika, te tako izdvaja sledeće: (1) sfera interesovanja rečnika, (2) broj jezika obrađenih u rečniku, (3) obuhvaćena leksička masa, i (4) način predstavljanja leksičke mase. Prema prvom, rečnike deli na lingvističke i nelingvističke odnosno na rečnike i enciklopedije, prema drugom na jednojezičke, dvojezičke i višejezičke rečnike, prema trećem kriterijumu, rečnici su opšti i posebni (ovi drugi mogu biti veoma različitog karaktera, npr. istorijski, dijalekatski, terminološki, tvorbeni, frazeološki, itd.), a prema četvrtom, generalni (opisni) i specijalni (npr. preskriptivni, učenički, obrnuti, slikovni rečnici itd.).

Kostić-Tomović (2017: 170) deli rečnike prema sledećim opštim kriterijumima: ${ }^{3}$

\footnotetext{
${ }^{3}$ Kostić-Tomović (2017: 171) napominje da neki rečnici mogu biti receptivni ili produktivni, pa čak i oba istovremeno, kao što je to slučaj dvojezičnih rečnika opšte upotrebe. Ipak, autorka podseća da su potrebe ciljnih grupa (korisnika polazišnog i odredišnog jezika) različite.
} 


\begin{tabular}{|l|l|}
\hline \multicolumn{1}{|c|}{ Kriterijumi } & \multicolumn{1}{c|}{ Tipovi rečnika } \\
\hline \multirow{2}{*}{ medij } & štampani \\
\cline { 2 - 2 } priroda informacija & elektronski ili digitalni \\
\hline \multirow{3}{*}{ broj jezika } & jezički \\
\cline { 2 - 2 } & nejezički (enciklopedije) \\
\cline { 2 - 2 } jednojezični \\
\cline { 2 - 2 } samostalnost & višejezični \\
\hline \multirow{2}{*}{ struktura } & samostalni \\
\cline { 2 - 2 } & nesamostalni (npr. glosari) \\
\hline \multirow{2}{*}{$\begin{array}{c}\text { suštinski tip / tipovi } \\
\text { informacija }\end{array}$} & semasiološki \\
\cline { 2 - 2 } & onomasiološki \\
\cline { 2 - 2 } & opšti \\
\hline \multirow{2}{*}{ specijalizovani } \\
\hline
\end{tabular}

Taksonomija rečnika (Kostić-Tomović 2017)

Autorka podseća da jedan rečnik ne pripada samoj jednoj grupi već se može svrstati u više njih, jer su kriterijumi komplementarni a ne isključivi; tako, na primer, jedan rečnik može da bude štampani (prema vrsti medija), jezički (prema prirodi informacije), jednojezični (prema broju jezika), samostalan (prema kriterijumu samostalnosti), semasiološki (prema strukturi) i specijalizovani (prema tipu informacije, na primer, frazeološki rečnik). Pri tom, ukoliko bi se kao kriterijumi dodali produktivnost / receptivnost i tip korisnika, rečnik bi, na primer, mogao biti i receptivnog tipa, namenjen odraslim korisnicima.

Posebno je heteregena grupa rečnika koji se dele na opšte i specijalizovane odnosno posebne ili restriktivne, od kojih ovi drugi opet mogu biti veoma heterogeni; tako su posebni rečnici sinonima i antonima, frazeološki i kombinatorni rečnici, terminološki i mnogi drugi. Porto Dapena (2002: 59) skreće pažnju na to da atributi opšti i posebni odnosno restriktivni ne podrazumevaju manji ili već broj odrednica, već razliku u obimu leksike koja je obrađena. Opšti rečnici pak, kako navodi autor, mogu biti iscrpni ali i selektivni, poput priručnih i džepnih rečnika. 


\subsection{Dvojezični rečnici}

Dvojezični rečnici ${ }^{4}$ predstavljaju izuzetno značajno oruđe $u$ obrazovanju i čine most između govornika različitih jezika, srodnih ili nesrodnih (Vinja 2017: V; Kocjančič 2004: 174). Prema Zgusti (1991: 280), „vjerovatno najvažnija dimenzija tipologije dvojezičnih rječnika sastoji se u leksikografovoj namjeri da sastavi rječnik: kao pomagalo u shvatanju tekstova u izvorišnom jeziku, ili kao opis izvorišnog jezika, ili kao pomoć za stvaranje tekstova na odredišnom jeziku“. Zgusta navodi da, iako obično ima u vidu jednu od navedenih dimenzija, leksikograf uvek nastoji da obuhvati i ostale, tako da rečnik uglavnom zadovoljava više potreba. Kada je u pitanju obim dvojezičnog rečnika (koji je, najčešće, manjeg obima u odnosu na jednojezični rečnik), napominje da on ne treba da bude prekratak, ta da su „mali rječnici korisni samo za prilično ograničene svrhe, kao što su primitivne upotrebe turiste ili teških početaka učenja“. Najzad, autor podseća da je veoma važna komponenta dvojezičnog, baš kao i jednojezičnog rečnika, njegova namena, jer leksikograf mora da ima u vidu, između ostalog, da li će budućim korisnicima rečnik biti potreban za književno prevođenje, poslovnu korespondenciju ili pak za neku opštu upotrebu, te da li će korisnicima služiti za kodiranje ili dekodiranje značenja.

Prema Ernandes Ernandesu (2000: 93), dvojezični rečnici namenjeni su onima koji počinju da uče određeni strani jezik i služe im za razotkrivanje tj. razumevanje teksta odnosno značenja na stranom jeziku, što ne znači da "garantuju“ i adekvatno kodiranje odnosno produkciju na stranom jeziku. Ernandes, dakle, podvlači razliku između rečnika namenjenih recepciji i produkciji, odnosno pasivnih i aktivnih rečnika. Autor je mišljenja da dvojezični rečnici nisu odgovarajući na višim nivoima poznavanja stranog jezika, te da ih treba zameniti jednojezičnim rečnicima, i to onima namenjenim upravo učenju stranog jezika (learners' dictionaries), ukoliko postoje, a zatim rečnicima opšte upotrebe, kada strani govornik potpuno samostalno vlada stranim jezikom (Ernandes Ernandes 2000: 94, 96).

Ipak, ima istraživanja koja pokazuju da korisnici radije koriste dvojezične nego jednojezične rečnike (npr. 90-ih godina XX veka Atkins \&

\footnotetext{
${ }^{4}$ Dvojezični rečnici se nazivaju i prevodnim, te se tako govori i o dvojezičnoj ili prevodnoj leksikografiji. Radić-Dugonjić (2002: 343) objašnjava da je adekvatnije govoriti o prevodnim rečnicima, zato što „atributom prevodni određuje se tip rečnika koji je urađen po ustanovljenim metodama, dok atribut dvojezičan ukazuje prvenstveno na broj jezičkih sistema".
} 
Knowles, Meyer \& Roberts, te Corpas, Leiva \& Varela 2001, apud Ruhstaller 2005). Kocjančič (2004: 175) iznosi da, iako korisnici u jednojezičnom rečniku mogu da pronađu definiciju određene reči ili mogu da poznaju njeno značenje, nekada jednostavno ne mogu da se sete ekvivalentne i precizne reči u maternjem jeziku, i upravo tu dolazi do izražaja značaj kvalitetnog dvojezičnika. I prema Ruštaleru (2005), dobar dvojezični rečnik može da posluži ne samo za razumevanje značenja određenih reči ili izraza već i za kodiranje značenja na stranom jeziku, i to brzim pronalaženjem odgovarajućeg ekvivalenta, za čije iznalaženje bi mu bilo potrebno mnogo više vremena ukoliko bi konsultovao jednojezični rečnik, koji po svojoj prirodi umesto ekvivalenata nudi opise značenja. Ruštaler dodaje i da je uvreženo mišljenje da upotreba maternjeg jezika u nastavi stranog jezika često ide na štetu učenja stranog jezika, te je i to jedan od razloga zbog kojih se savetuje upotreba jednojezičnika. Autor, pak, smatra da maternji jezik neminovno čini polaznu tačku u učenju stranih jezika i da njegovo dobro poznavanje i razumevanje može da olakša i pozitivno utiče na učenje drugih jezika.

\subsection{Višejezični rečnici}

Višejezični rečnici se usled problema ekvivalentnosti uslovljenih anizomorfizmom jezika odnosno „razlikama u organizaciji designata $u$ pojedinim jezicima“ bave „samo nekim ograničenim skupovima riječi bez polisemije, kakva je naučna terminologija, ili je jednostavno odbacuju i navode samo dominantne smislove određenih riječi“ (Zgusta 1991: 275, 278). Ovi rečnici, dakle, imaju „usku sferu primene“ (Šipka 2006: 162), ali su veoma korisno oruđe za rad stručnjacima iz odgovarajućih tehničkih i naučnih oblasti, i izuzetno potrebna prevodilačka alatka.

\section{Leksikografska ostvarenja koja uključuju španski i srpski jezik}

Budući da osnivanje studijskih grupa za španski jezik i književnost na prostoru bivše Jugoslavije datira iz perioda 60-tih i 70-tih godina XX veka (v. Soldatić 2011), kada je u upotrebi bio termin srpskohrvatski ili hrvatskosrpski jezik, to znači da, pre nego što navedemo špansko-srpske / srpsko-španske rečnike objavljene kod nas moramo da se osvrnemo na srpskohrvatsku leksikografiju ${ }^{5}$. Šipka (2006: 176-177) razlikuje dve

\footnotetext{
${ }_{5}^{5}$ Šipka (2006) navodi da su se hrvatska i srpska leksikografija razvijale u različitim socioistorijskim okvirima, te da je hrvatska leksikografija starija, naprednija, kvalitetnija i raznovrsnija.
} 
faze srpskohrvatske leksikografije: dovukovsku, u kojoj hrvatski i srpski postoje kao zasebni tokovi, i postvukovsku, u kojoj se ova dva toka prepliću u srpskohrvatski, iako neki rečnici i dalje nose naziv jednog ili drugog jezika. Ovaj period, kako navodi Šipka (2006: 177), traje do 90-ih godina prošloga veka, odnosno do raspada bivše Jugoslavije, kada počinje postjugoslovenska faza. ${ }^{6}$

\subsection{Dvojezični rečnici koji uključuju španski i srpskohrvatski jezik}

Prvi dvojezični rečnik sa španskim i srpskohrvatskim jezikom jeste Džepni špansko-srpskohrvatski rečnik sa kratkom gramatikom španskog jezika autora Branislava Grujića ${ }^{7}$, objavljen 1962. godine u Beogradu i Cetinju, kod izdavačkih kuća Prosveta i Obod. Rečnik, malog formata i obima, ${ }^{8}$ sadrži 30.000 odrednica predstavljenih na 392 strane. Na početku rečnika je spisak korišćenih skraćenica, zatim spisak korišćene literature, a posle rečnika, od strane 361, sledi kratak pregled španske gramatike. U odeljku posvećenom glagolima, uz svaki nepravilni glagol naznačena je grupa kojoj pripada (od I do VI), u zavisnosti od nepravilnosti kojom se odlikuje. Rečnik je uređen po etimološkim gnezdima a prema prvoj reči koja dolazi po abecednom redu; tako u okviru abandonado nalazimo i abandonar, abandonarse, abandono; u okviru humanar su i humanidad, humanismo, humanitario, humanitarismo, humano; itd. Rečnik beleži i brojne konstrukcije (terminološke sintagme, frazeme, kolokacije, ustaljene formule, pa čak i poneku poslovicu), poput sledećih:

buque (...) buque de guerra ratni brod, buque mercante trgovački brod, buque de vapor parobrod, buque de vela jedrenjak, buque portaviones nosač aviona, buque tanque tanker;

hijo (...) cada uno es hijo de sus obras što poseješ to ćeš i požnjeti;

\footnotetext{
${ }^{6}$ Prvi rečnik španskog jezika objavljen na prostoru bivše Jugoslavije jeste Španjolskohrvatski priručni rječnik hrvatskog književnika i prevodioca Ise Velikanovića. Rečnik je objavljen u Zagrebu 1928. godine, na 242 strane. Naredne godine, 1929, isti autor objavio je i Hrvatsko-španjolsko priručni rječnik, takođe u Zagrebu, na 343 + XLI strane.

${ }^{7}$ Iako ne raspolažemo dovoljnim i pouzdanim podacima, rekli bismo da Grujić nije hispanista, jer je krajem 50-ih i početkom 60-tih godina prošloga veka objavio, samostalno ili u koautorstvu, dvojezične rečnike za jezičke parove srpskohrvatski i engleski / nemački / francuski / italijanski / ruski itd., u oba pravca, sa sažetim gramatičkim objašnjenjima, nakon kojih je usledio i rečnik koji uključuje i španski jezik.

${ }^{8}$ Prema obimu, opšti dvojezični rečnici mogu biti džepni (od 5.000 do 15.000 odrednica), mali (od 15.000 do 35.000 odrednica), srednji (od 35.000 do 60.000 odrednica) i veliki (preko 60.000 odrednica) (Kocjančič 2004).
} 
pelo (...) pelo de gato sitna kiša, con todos sus pelos y señales sa svim pojedinostima, tener pelos en el corazón biti neustrašiv, ir a pelos ići gologlav; itd.

Sporadično se upotrebljavaju i glose, odnosno sažeta leksikografska pojašnjenja u zagradama, koja se najčešće odnose na domen upotrebe reči i preciziraju njeno značenje; na primer:

horcar vt. vešati (pogubiti)

bulto (...) escurrir (guardar, huir) el bulto skrivati se (od rada), izbegavati susret;

burbuja f. mehur (vazduha, vode); itd.

Tri godine kasnije, 1965, iste izdavačke kuće objavile su i rečnik u suprotnom pravcu, srpskohrvatsko-španski (Džepni srpskohrvatskošpanski rečnik / Diccionario manual servocroata-español). I ovaj rečnik je malog formata i obima. Na početku rečnika data su „Pravila za čitanje“, a potom spisak skraćenica. I ovaj rečnik je uređen po etimološkim gnezdima; na primer, u okviru odrednice prvi nalazimo i složenice prvobitan, prvoborac, prvorazredan, pod odrednicom uspeh se beleži i uspešan, uspešno, uspehovati, itd. Korisnici rečnika će i ovde naići na ustaljene i terminološke sintagme, poput astronomska godina, prestupna godina, tekuća godina, budžetska godina, školska godina itd. (pod odrednicom godina), pružiti ruku, pružiti pomoć (u okviru pružiti), ptica grabljivica, ptica pevačica (u okviru ptica), itd. I u ovom rečniku je važno ukazati na upotrebu glosa; na primer:

gazda (...) (3) (bogataš) hombre rico (4) (poslodavac) patrono, m. patrón m. odsustvo (...) (3) (odmor) vacaciones fpl.

U rečniku su zabeleženi i neki toponimi i nazivi nacionalnosti (npr. Atlantik, Belgija, Čeh, Kina, Španija itd.).

Po raspadu nekadašnje Jugoslavije, Grujićevi rečnici objavljeni su kao špansko-srpski odnosno srpsko-španski: Džepni špansko-srpski rečnik sa kratkom gramatikom španskog jezika (Cetinje: Obod, 1994), Džepni srpsko-španski rečnik (Cetinje: Obod, Beograd: Draganić, 1999).

Godine 1971.objavljen je i do dan-danas najobimniji rečnikšpanskog jezika na prostorima bivše Jugoslavije, Španjolsko-hrvatskosrpski rječnik $s$ osnovama španjolske gramatike i španjolskog trgovačkog dopisivanja autora Vojmira Vinje, u saradnji sa Ratiborom Musanićem. Vinja je bio 
istaknuti hrvatski lingvista, romanista, začetnik studija hispanistike u Zagrebu (1969. godine). ${ }^{9}$ Pomenuti rečnik je objavljen u Zagrebu, u izdavačkoj kući Školska knjiga, na XV + 1132 strane, a namenjen je prevashodno studentima hispanistike i romanistike. Kao što se vidi iz naslova, rečnik sadrži i osnove španske gramatike i primere i obrasce trgovačke korspondencije, kao i spisak učestalih skraćenica u zemljama španskog govornog područja. Značajno je naglasiti da leksikografski članci Vinjinog rečnika sadrže i ustaljene izraze i terminološke sintagme, što čini ovaj rečnik još vrednijim za njegove korisnike. Vinja se osvrće i na problem određivanja onoga što bi se moglo nazvati standardom španskog jezika, a usled velike raslojenosti ovoga jezika: „umjesto više-manje određenog k o r p u s a normiranog rječnika morali smo dati što bogatiji p o p i s oblika koji su u živoj upotrebi od Kastilije i Andaluzije do Filipina i Ognjene zemlje" (Vinja 2017: V). Rečnik je do sada imao 6 izdanja ${ }^{10}$, a od 3. izdanja, iz 1991. godine, po raspadu bivše Jugoslavije, u naslovu rečnika je naziv hrvatski jezik.

Vojmir Vinja je, u saradnji sa Rudolfom Kožljanom, objavio i Langenscheidtov univerzalni rječnik. Španjolsko-hrvatskosrpski, hrvatskosrpsko-španjolski, 1972. godine (Zagreb: Mladost). Malog formata, rečnik se sastoji od oko 30.000 odrednica, na početku sadrži sažete podatke o izgovoru i pisanju u španskom jeziku, dok se na kraju nalazi spisak nekih španskih skraćenica, brojevi, razlomci, računske radnje, ustaljene i učestale konstrukcije karakteristične za neke svakodnevne komunikativne situacije, a zatim i spisak naziva nekih jela i namirnica (uključujući, na primer, nazive nekih riba, divljači, živine itd. na oba jezika, pa čak i nekih španskih nacionalnih jela).

Sva tri objavljena dvojezična rečnika su opšteg tipa, s tim što su prvi (Grujićev) i treći (rečnik Vinje i Kožljana) selektivni.

U jugoslovenskoj odnosno srpskohrvatskoj fazi objavljen je i jedan terminološki (dakle, restriktivni, specijalizovani) rečnik, i to Leksikon društveno-političke i samoupravne terminologije: srpskohrvatsko-španski, 1977. godine (Beograd: CAS). ${ }^{11}$ Autor je Novak Strugar, dok je prevodilac na španski Argentinac Huan Oktavio Prens (Juan Octavio Prenz), inače jedan od prvih stranih lektora na studijskoj grupi Španski jezik i književnost, osnovanoj 1971. godine pri Katedri za romanistiku Filološkog fakulteta

\footnotetext{
${ }^{9}$ http://www.ffzg.unizg.hr/roman/odsjek/povijest-odsjeka/

${ }^{10}$ I izdanje je iz 1971, II iz 1985, III iz 1991, IV iz 2000, V iz 2005. i VI iz 2017. godine.

11 Iste godine su objavljeni i srpskohrvatsko-nemački, srpskohrvatsko-francuski, srpskohrvatsko-italijanski i srpskohrvatsko-ruski leksikoni, dok je isto leksikografsko delo za srpskohrvatsko-engleski jezik objavljeno dve godine kasnije.
} 
(Soldatić 2011: 31). Leksikon kao odrednice uvršćuje i proste i složene leksičke jedinice odnosno kolokacije, ustaljene i terminološke sintagme (npr. 'vanklasna politika', 'akcioni plan', 'verifikacija mandata', itd.), pa čak i naslove, slogane itd., koji se stavljaju pod uglaste navodnike («Dečja bolest levičarstva u komunizmu», «Fabrike radnicima», itd.). Zanimljivo je pomenuti da u okviru prostih odrednica (koje su pre svega imenske, ređe pridevske) autor navodi i reči i sintagme uz koje odrednička reč kolocira; na primer, akumulacioni, amortizacioni, investicioni, proizvodni, socijalnog osiguranja, stambeni, za kreditiranje, zajedničke potrošnje, zajedničkih rezervi nabrojani su u okviru odrednice fond.

\subsection{Dvojezični špansko-srpski / srpsko-španski rečnici}

Od 90-tih godina XX veka u Republici Srbiji je objavljeno 20 dvojezičnih rečnika koji uključuju španski i srpski jezik. U pitanju su selektivni rečnici opšteg tipa (priručni i džepni), posebni, konkretnije terminološki rečnici, a zatim i specijalni, i to slikovni i ilustrovani.

Zoja Stojanovići Ivana Stojanović potpisuju autorstvo Džepnog srpsko španskog rečnika, objavljenog 1995. godine (Beograd: Pirg, Svjetlost-B). Rečnik je malog formata, a objavljen je u tiražu od 1.500 primeraka. Na početku rečnika nalazi se španska abeceda, sa nazivom slova i izgovorom, a potom na dve strane sledi opis izgovora i pravila akcentovanja. Autorke naglašavaju i upotrebu obrnutih upitnika i uzvičnika na početku rečenice u španskom jeziku i navode skraćenice (samo za $\operatorname{rod}^{12}$ ) kao i to da član el označava muški rod imenice, a la ženski rod imenice. Posle srpsko-španskog rečnika sledi dodatak, u kome se registruju pozdravi, oslovljavanje, izrazi učtivosti, nazivi za dane i mesece, prosti i redni brojevi, nazivi nekih zanimanja, imena gradova koji se izgovaraju drugačije nego na srpskom jeziku, itd. Uočavaju se manje slovne greške i propusti u grafičkom akcentu (npr. veintidos, veintitres umesto veintidós, veintitrés, itd.). Rečnik sadrži i složene odrednice, među kojima ima kako ustaljenih tako i slobodnih sintagmi (prokrčiti put, sklapati prijateljstva, sklapati ugovor, telesna vežba, viseći most, vozna karta, povesti parnicu, povratak u domovinu, površina vode itd.).

Kao što smo kazali, Džepni špansko-srpski rečnik sa kratkom gramatikom španskog jezika autora Branislava Grujića objavljen je 1994. godine kod izdavačke kuće Obod iz Cetinja (tiraž 2.000 primera), a Džepni srpsko-španski rečnik istog autora objavili su Obod i Draganić (Cetinje i

${ }^{12}$ Navodi se i skraćenica za srednji rod, što može da navede na pogrešnu pomisao da $u$ španskom jeziku postoje imenice srednjeg roda. 
Beograd) 1999. godine (tiraž 1.000 primeraka). Grujić je autor i „novog standardnog rečnika" Nuevo diccionario estándar español-serbio serbioespañol / Novi standardni rečnik špansko-srpski srpsko-španski iz 2001. godine, objavljenog kod izdavačke kuće Jasen iz Nikšića. Rečnik je štampan u tiražu od 2.000 primeraka, na 1023 strane, a korekturu i doradu su potpisale Nataša Romanić i Violeta Stepanović. Već na koricama se može pročitati da rečnik sadrži „preko 100.000 reči, izraza, fraza i sinonima sa kratkom gramatikom španskog jezika i tematskim tabelama“. Dakle, osim dva dela rečnika, ova publikacija obuhvata i gramatički dodatak (na čak 200 strana), rečnik sinonima (str. 503-697), oblike pravilnih i nepravilnih glagola i slikovni rečnik (str. 903-1023). Rečnik je uređen tako da se u okviru jednog leksikografskog članka nalaze reči iz istog etimološkog gnezda, kao i ustaljene konstrukcije i poneki frazeološki izraz. Na primer, pod odrednicom palabra nalaze se, između ostalog, i empeñar la palabra, palabra pesada, beber las palabras itd.; u okviru odrednice biblioteka nalaze se sintagme javna biblioteka i pokretna biblioteka, kao i imenica bibliotekar. Kao i u džepnim rečnicima koji su prethodili standardnom rečniku, autor se služi glosama, navedenim u zagradama, poput sledećih:

natural adj. (...) naturalismo (...) 2 naturalizam (u književnosti, filosofiji) naipada $f(.$.$) naipe m$ karta (za igranje)

šaka $f(. .$.$) (količinski) puńado m$, manípulo $m$ gaćan adj (golub) (zool.) pichón.

Grujićev rečnik preštampan je 2002. godine, kod iste izdavačke kuće. Rečnik istoimenog naslova, čije autorstvo osim Branislava Grujića potpisuje i Marijana Srđević, objavio je 2006. godine Obod Cetinje, u istom tiražu, ovoga puta na 944 strane. Rečnik je preštampan 2007. godine, na Cetinju (Obod) i u Beogradu (Predrag i Nenad), u tiražu od 2.500 primeraka, i vodi se kao 3. izdanje. Četvrto izdanje, u tiražu od 1.000 primeraka objavile su iste izdavačke kuće 2011. godine, a rečnik je zadržao uređenje odrednica prema etimološkim gnezdima.

Prvi specijalizovani, konkretnije poslovni, rečnik španskog i srpskog jezika delo je autorke Karmen Vegas de Spalajković, pod naslovom Business rečnik špansko-srpski: srpsko-španski (Beograd: Žarko Albulj). Objavljen je 1997. godine. Autorka u sažetom predgovoru navodi da je tržište uslovilo potrebu za rečnikom „koji bi poslovnim ljudima približio ekonomskoposlovnu terminologiju", budući da za poslovnu korespondenciju, kako s pravom navodi autorka, nije dovoljno „opšte poznavanje jezika“. Rečnik 
sadrži oko 7.500 stručnih reči i izraza, a štampan je u tiražu od 1.000 primeraka.

Godinu dana kasnije, 1998, Jasmina Boričić objavila je Špansko-srpski i srpsko španski rečnik (sa osnovama španske gramatike), a izdavač je JRJ iz Zemuna. Rečnik je štampan u tiražu od 3.000 primeraka. Prema podacima do kojih smo mogli da dođemo uvidom u bibliotečke fondove, nijedan drugi rečnik nije doštampavan koliko ovaj: ima 10 izdanja. ${ }^{13}$ U Predgovoru autorka kaže da je rečnik „namenjen svima onima koji žele da ovladaju španskim jezikom, a smatraju da im je za to dovoljno oko 10.000 reči“ (str. 4). Rečnik, kako se navodi, omogućava prevođenje raznovrsnih tekstova, a koncipiran je tako da omogućava jednostavnu pretragu. Tome doprinosi i podatak da su „uz pojedine pojmove, da bi se lakše koristili, dodate [su] složenice koje se najčešće vezuju za taj pojam" (str. 4). Kao što se vidi iz naslova, rečnik sadrži i „skraćeni gramatički dodatak koji je prilagođen zahtevima korisnika za što jednostavniju upotrebu" (str. 4). Posle Predgovora sledi spisak španskih i srpskih skraćenica ${ }^{14}$ korišćenih u rečniku. Između dva dela rečnika nalazi se deo nazvan „Osnovi španske gramatike“, koji obuhvata preko 50 gramatičkih tema, počev od diftonga, triftonga i pravila naglašavanja u španskom jeziku, preko roda i broja imenica i prideva, do glagolskih oblika. Na kraju rečnika je spisak korišćene literature, što pokazuje da je rečnik rezultat promišljenog i stručno utemeljenog rada. Primećujemo da autorke uvršćuju frazeološke konstrukcije unutar odrednice (npr. al alire libre, de mal aire, fundar en el aire itd. u okviru odrednice aire, tener buenas aldabas, agarrarse a buenas aldabas $\mathrm{u}$ okviru odrednice aldaba, itd.), što, $\mathrm{u}$ principu, doprinosi kvalitetu rečnika. Kada je u pitanju srpsko-španski deo rečnika, autorka u okviru iste odrednice uvršćuje reči iste tvorbene osnove, i onda kada one čine deo ustaljenih veza reči ${ }^{15}$, pa tako na primer u okviru jedno|dušan nalazimo i jednoglasan, jednoličan, jednom, još jednom, jednoredan, jednoruk, jednostavan, jednostavno, u okviru pau|čina nalazimo pauk, u okviru pouč|avati stoji i poučan, u okviru potroš|ač je uvršten i glagol potrošiti, itd.

Španski slikovni rečnik priređivača Bruna Vajsa objavila je 2002. godine izdavačka kuća Alnari i Ateneum iz Beograda, u tiražu od 500 primeraka. Rečnik ne sadrži uvod, a osmišljen je tako da izgleda kao

\footnotetext{
${ }^{13}$ Posle njega, Novi standardni rečnik špansko-srpski / srpsko-španski Branislava Grujića i Špansko-srpski / srpsko-španski rečnik Vojislava Nikolića do sada su preštampani 5 puta (u bibliotečkom zapisu stoji da su izdanja ovih rečnika iz 2011. odnosno 2019. godine u štampi i da ne postoje primerci ove građe ni u jednoj biblioteci u COBISS.SR sistemu).

${ }^{14}$ I ovde se uočavaju neke slovne greške, poput *ambigno umesto ambigüo, *despertivo umesto despectivo itd.
}

${ }^{15}$ Na primer pečeni krompir (pod pečen), anđeo čuvar (pod anđeo), alkoholno piće (pod alkohol) itd. 
bojanka (ilustracije je radio Zoran Davidović), na 32 strane + indeks. Pokriva 14 tema (na primer, prevozna sredstva, zoološki vrt, u parku, na plaži, itd.), posle kojih sledi „Index“ (strane 33-36), u kome se na početku pojašnjava upotreba oblika $e l, l a$, los i las uz reči, te način obeležavanja izuzetaka i naglašenog sloga ${ }^{16}$.

Pod pokroviteljstvom ambasade Španije odnosno Španske agencije za međunarodnu saradnju, Foto Futura iz Beograda objavila je 2003. godine džepni Špansko-srpski srpsko-španskididaktički rečnik/Diccionario didáctico español-serbio serbio-español. Urednici su Jelena Filipović i Sesar Dijes Plasa (César Díez Plaza), a prevoditeljke su Vesna Mastalo i Ivana Šekularac Popović. Korekturu potpisuju Maja Andrijević i Hugo Marcos Blanco. Ovaj „bazični” rečnik, kako ga sami urednici karakterišu, namenjen je onima koji počinju učenje španskog odnosno srpskog jezika, s ciljem da „postane nezaobilazno sredstvo u prvim fazama učenja jednog ili drugog jezika" (str. 8). Posle Uvoda sledi spisak korišćenih skraćenica i principi predstavljanja odrednica u rečniku, gde se uključuje i primer strukture jedne odrednice u rečniku. Navedene su, paralelno, abecede španskog i srpskog jezika, bez opisa izgovora glasova. Između dva dela rečnika nalazi se nekoliko stranica s leksičkim i gramatičkim temama u španskom jeziku (spisak osnovnih brojeva i naziva za dane u nedelji, mesece u godini, godišnja doba, zatim nekolicina korisnih izraza, nazivi narodnosti i spisak glagolskih perifraza, ilustrovanih primerima i njihovim prevodima). Na kraju rečnika se nalazi spisak korišćene literature, u kojoj su popisani praktično svi kod nas prethodno objavljeni rečnici španskog i srpskog jezika. U rečniku nismo primetili prisustvo ustaljenih izraza, ali se ponegde uočava upotreba glosa; na primer:

aborrecer $v$ (...) napustiti (gnezdo); alfil $m$ trkač $^{17}$ (figura u šahu); dar $v$ dati; davati (plodove); otkucati (o satima); zaželeti (dobrodošlicu ili dobar dan); itd.

Glose su nekada navedene uz odredničku reč umesto $u$ odgovarajućem značenju:

badem (drvo) $m$ almendro $m$; iščeznuti (o mrljama) $v$ salir;

ljubazan (prema ženama) adj galante; itd.

\footnotetext{
${ }^{16}$ Uočavaju se greške na nekim mestima, kao npr. u panaderia (bez grafičkog akcenta na $i$ ), gde se kao naglašeni slog pogrešno označava e: panaderia. Ima i grešaka drugog tipa, kao npr. frutas enlastadas (umesto enlatadas), helado " ${ }^{* k}$ kornet za sladoled“ itd.

${ }^{17}$ lovac
} 
U srpsko-španskom delu rečnika primećuje se upotreba složenih odrednica, različitog tipa, kao npr. ludovati za nekim, ljubav na prvi pogled, razviti fotografije, širiti glasine, školska klupa, itd. Rečnik je preštampan $2004 .{ }^{18}$

Marijana Panžić i Biljana Kovačević priredile su Špansko-srpski $i$ srpsko-španski rečnik, objavljen 2004. godine ${ }^{19}$ (Beograd: Duška), štampan ćiriličnim pismom. Rečnik je preštampan 2007. godine, u istoj izdavačkoj kući i u istom tiražu od 1.000 primeraka. U pitanju je džepni rečnik malog formata. Izdanje iz 2004. godine štampano je na 370, a izdanje iz 2007. godine na 308 strana. Priređivačice navode da ovaj rečnik „treba da koristi turistima kao praktičan priručnik prilikom vođenja svakodnevnih razgovora i pri čitanju lakših tekstova“. Makrostruktura i ovog rečnika je alfabetska, a rečniku prethodi spisak skraćenica ${ }^{20}$ (iz pravca od španskog ka srpskom), a potom i španska abeceda (slovo, naziv slova i izgovor). Na spisku skraćenica ne možemo a da ne primetimo greške poput istoria (umesto historia), fizica (umesto física), kao i skraćenicu intr. koja se prevodi kao „neodređeno“ (umesto „neprelazni (glagol)“) i v. (transitivo), koja je rastumačena kao „prolazan“ (umesto „prelazni (glagol)“). U izdanju iz 2007. godine donekle je izmenjen odeljak o španskoj abecedi.

Dragana Tošić je autorka Srpsko-španskog rečnika pravnih i poslovnih termina / Diccionario de términos jurídicos y de negocios serbio-español, koji je 2005. godine objavila izdavačka kuća iz Beograda Službeni glasnik, u tiražu od svega 500 primeraka. Iz uvodnog teksta vidimo da je ovaj rečnik recenzirao dr Dalibor Soldatić, u to vreme vanredni profesor na Katedri za iberijske studije Filološkog fakulteta u Beogradu, ali i iskusni književni prevodilac, te simultani i konsekutivni prevodilac neknjiževnog diskursa odnosno „stručnih“ tekstova. Smatramo značajnom napomenu dr D. Soldatića u prvim redovima njegovog teksta, kada kaže: „Zadatak autora bio je izuzetno težak s obzirom na okolnost da nije imao na raspolaganju podatke o korisnicima kojima je takav rečnik namenjen, njihovom obrazovanju i potrebama, kako bi shodno rezultatima tih analiza odredio konfiguraciju svog rečnika“. Iako nije leksikograf, ali jeste neko ko radi s rečnicima, te ume da prepozna njihov značaj, kao i značaj različitosti ovih leksikografskih dela s obzirom na korisničke potrebe, dr D. Soldatić iznosi ovu dragocenu napomenu kao neko ko se i sâm susreo s brojnim prevodilačkim zadacima, u kojima je bilo potrebno pronaći tačan i precizan

\footnotetext{
${ }^{18} \mathrm{U}$ pitanju su besplatni primerci.

${ }^{19} \mathrm{U}$ rečniku stoji 2003. godina.

${ }^{20}$ Izostaje spisak skraćenica iz pravca od srpskog ka španskom, jer ih i nema uz reči na srpskom jeziku.
} 
ekvivalent. Autorka u predgovoru navodi niz specijalizovanih rečnika kojima se služila prilikom izrade ovog srpsko-španskog rečnika pravnih i poslovnih termina, i sažeto objašnjava kako je koncipiran rečnik. Kaže, takođe, da je obuhvaćena leksika iz oblasti prava, trgovine, poslovanja, finansija, bankarstva, osiguranja, obrazovanja, zatim društveno-politička terminologija, ali i reči i izrazi iz savremenog jezika koji su prisutni u medijima i međunarodnoj komunikaciji. Nakon spiska skraćenica sledi srpsko-španski rečnik, koji sadrži preko 27.000 odrednica.

Iste godine kada je objavljen ovaj posebni rečnik, objavljen je i selektivni rečnik opšteg karaktera Špansko-srpski / srpsko-španski rečnik koji je priredio Vojislav Nikolić, kod izdavačke kuće Jasen iz Beograda. Lekturu je radila Erminija Koredera-Gerber (Herminia Corredera-Gerber). Kako se vidi iz CIP-a, ovo je, prema Predgovoru, 1. izdanje, a štampano je u tiražu od 2.000 primeraka, na 1.124 strane. Prvo izdanje rečnika je preštampano 2006. godine (u tiražu od 2.000 primeraka), iz 2010. godine datira 2. izdanje (u tiražu od 1.000 primeraka), dok je 2014. godine objavljeno 3. izdanje (u tiražu od 1.000 primeraka). Predgovor svakom od pomenutih izdanja je praktično isti, uz neznatne razlike $u$ formulacijama nekoliko rečenica. Nije navedeno koji broj odrednica beleži rečnik. Ispred svakog od dva glavna dela rečnika nalazi se spisak skraćenica, dok se između njih nalazi „Rečnik sinonima“ (strane 571-780) i „Kratka gramatika španskog jezika" (strane 781-932). Na kraju je uvršten i slikovni rečnik (str. 1320-1431), kome prethodni spisak skraćenica. Iz zapisa u COBISS-u vidimo da je 2019. godine u štampi bilo još jedno, 4 . izdanje, u istom tiražu od 1.000 primeraka i na istom broju strana, ali primerci još uvek nisu dostupni u bibliotekama.

Biljana Romčević priredila je Ilustrovani rečnik španskog jezika, koji su 2006. godine objavili Teatar Za iz Beograda i Liber iz Novog Sada, na 93 strane, u tiražu od 500 primeraka. Iz predgovora saznajemo da je rečnik namenjen „deci koja počinju da uče španski jezik“ i da je kreiran „kao savremeno nastavno sredstvo i koristan priručnik“. Napominje se i da je rečnik u skladu s planom i programom za učenje jezika na početnom nivou (premda se ne navodi na koji plan i program se tačno misli), te da je sastavljen po uzoru na „moderne svetske rečnike tog tipa“. Reči su grupisane tematski, a na kraju se nalazi „indeks svih reči navedenih u rečniku sa odgovarajućom transkripcijom“. Međutim, u „Rečniku pojmova“ reči nisu transkribovane, već je samo ponuđen njihov prevod na srpski jezik. Kod španske abecede („Alfabeto“) stoji transkribovan naziv svakog slova (bez ikakvih zagrada i fonetskih znakova), a ponegde je, u zagradi, dato sažeto pojašnjenje odnosno glosa. 
Milutin Stojanovićn ${ }^{1}$ je autor Rečnika fraza i opštih izraza: srpskošpanski. 55.000 terminoloških jedinica, koji je 2006. godine, u tiražu od 500 primeraka, objavila Građevinska knjiga iz Beograda. ${ }^{22}$ Lekturu i korekturu potpisuje priznata prevoditeljka hispanistkinja Biljana Bukvić. U uvodnoj napomeni, autor navodi da je 5 godina boravio na Karibima (konkretnije, na Kubi), gde je prikupljao i obrađivao građu za srpskošpanski opšti i frazeološki rečnik. Nakon uvodne napomene sledi rečnik, posle kojeg, od strane 931, ide odeljak „Španski alfabet“, zatim „Dani u nedelji“, „Godišnja doba“ i „Meseci u godini“ (na strani 933), a na kraju su uvršteni i „Neki rebusi-zagonetke (rešene)“ (str. 934-936), koje takođe sadrže prevod na srpski jezik. Kako stoji u naslovu, rečnik sadrži „opšte fraze“, odnosno veoma različite konstrukcije, uglavnom slobodne kombinacije reči (npr. bivši ambasador, često ponavljati, itd., a često sadrže glagol u ličnom glagolskom obliku, kao npr. stekao sam utisak, stekao je prednost od deset metara, situacija traži od svih, itd.), ali i neke kolokacije (npr. steći prijatelje, steći ugled, sticaj okolnosti itd.), pa čak i poslovice ili konstrukcije nalik njima (npr. Često onaj ko čeprka, nađe ono što nije hteo). „Fraze“ su poređane abecedno, prema prvoj reči, što za korisnike i nije naročito praktično.

Karmen (Carmen) Vegas de Spalajković je autorka Rečnika idioma i fraza: špansko-srpski srpsko-španski, koji je 2006. godine objavio Megatrend univerzitet u Beogradu, u tiražu od 200 primeraka, na 163 strane. Lekturu je radila hispanistkinja Đurđa Trajković. Pošto rečnik nema nikakav uvod, ne znamo koje vrste „idioma i fraza“ uključuje i koji je bio kriterijum njihovog odabira. Zanimljivo je i da izrazi, kojih ima 1.000, ne idu abecednim redosledom, ali su obeleženi brojevima. Uz svaki izraz se navodi primer, bez izvora, na osnovu čega zaključujemo da su primeri autorski. Na kraju rečnika nalazi se spisak svih španskih izraza, poređanih alfabetski, s ekvivalentom u srpskom jeziku, is rednim brojem, radi lakšeg nalaženja u rečniku. Iako u naslovu stoji špansko-srpski, srpsko-španski, izrazi ipak idu samo iz pravca od španskom ka srpskom jeziku.

U COBISS-u smo našli podatak o elektronskom špansko-srpskom / srpsko-španskom rečniku, iz 2007. godine, u izdanju Primatrona iz Novog Sada, čiji je urednik Dragan Božić, a saradnik Ilario Kastuera Montoro

\footnotetext{
${ }^{21}$ Autor je, kako se vidi iz njegovih uvodnih napomena, preveo na srpski jezik poeziju nekih kubanskih i latinoameričkih pesnika. Iz njegovih reči se stiče zaključak da nije hispanista, ali je očigledno da je upoznao španski jezik i kulturu govornog područja na kojem je boravio.

${ }^{22}$ Godine 1960, u istoj izdavačkoj kući, Stojanović je objavio sličan rečnik srpskog i engleskog jezika.
} 
(Hilario Castuera Montoro); međutim, prema zapisu, rečnik je i dalje u pripremi, tako da nemamo uvid u njegovu strukturu.

Veljko Nikitović potpisuje Srpsko-španski / špansko-srpski rečnik sa gramatikom, objavljen 2013. godine u Beogradu, kod izdavačke kuće Book. Štampan je u tiražu od 1.000 primeraka. Sadrži predgovor, spisak skraćenica, spisak korišćenih leksikografskih izvora, špansko-srpski rečnik, sažetu gramatiku španskog jezika i srpsko-španski rečnik. Kako navodi u Predgovoru, „[n]amera sastavljača je bila da odrednicama ovog rečnika obuhvati kako savremeni govorni jezik, koji u današnje vreme podrazumeva terminologiju osnovnih nauka i naučnih dostignuća, tako i standardni španski književni jezik, obogaćen frazeološkim izrazima, ali i familijarnim i figurativnim značenjem izvesnih reči i danas neizbežnim žargonskim odrednicama" (str. 7). Autor napominje i da ovaj rečnik predstavlja „skelet“ budućeg opšteg srpsko-španskog rečnika, koji bi trebalo da bude objavljen kako u štampanoj tako i u elektronskoj formi. Rečnik beleži i neke toponime (npr. nazive država, okeana, kontinenata), a značajan segment čine ustaljene konstrukcije i frazeološki izrazi uvršćeni u rečnički članak, kao, na primer, abalanzarse a los peligros u okviru orednice abalanzar, palabras mayores, comerse palabras, tomar la palabra, torcer las palabras u okviru odrednice palabra, nuklearni reaktor u okviru reaktor, poštansko sanduče u okviru sanduče, itd. I u ovom rečniku ističemo upotrebu glosa odnosno jezgrovitih leksikografskih pojašnjenja, u zagradama, koja se najčešće odnose na domen upotrebe, a koja umnogome olakšavaju razumevanje i pravilnu upotrebu odgovarajuće reči; na primer: pajear $v$ hraniti (konja) slamom; čačkati $v$ (zube) mondarse, (vatru) hurgar, hurgonear, (zadirkivati) burlar; itd.

Godine 2014. Milomir Kragović je uredio Džepni rečnik srpskošpanski, koji je objavila izdavačka kuća Jasen iz Beograda (ćiriličnim pismom), u tiražu od čak 16.000 primeraka. U ovom rečniku malog formata i obima primećuje se, osim reči iz opšteg leksičkog fonda, i prisustvo naziva nekih kontinenata, zemalja i njihovih naroda (npr. Amerika, Afrika, Poljska, Španija, Rusija; Amerikanac, Afrikanac, itd.). Leksikografski članci ponekad sadrže ustaljene izraze, terminološke sintagme, ali i slobodne sintagme, za koje se može oceniti da su smatrane korisnim za svakodnevnu upotrebu; na primer:

afera $f$. escándalo $m$; ljubavna afera aventura amorosa $f$; imati aferu sa tener una aventura con

burgija $f$. barrena $f$., taladro $m$.; burgija za kamen barrena $f$. cena $f$. coste $m$., precio $m$., monta $f$; po svaku cenu a toda costa; prodavati ispod cene malvender, vender a bajo precio; sniženje cena reducción de precios). 
Rečnik koristi odgovarajuće skraćenice (za leksičku kategoriju, rod i broj, nivo upotrebe, registar itd.), koje su izlistane na samom početku rečnika.

Iste godine, 2014, objavljen je i Dvojezični slikovni rečnik (španskosrpski), u Vulkan izdavaštvu iz Beograda. Urednik je Nenad Atanasković, a prevod potpisuju Dubravka Trišić i Svetlana Babović. Dakle, ne radi se o autorskom rečniku već o rečniku prevedenom na srpski jezik. Beleži više od 6.000 reči i fraza, podeljenih tematski (ljudi, izgled, dom, službe, kupovina, hrana itd.). ${ }^{23} \mathrm{Na}$ kraju rečnika se nalazi registar za svaki od jezika. Moderan grafički dizajn, boje i ilustracije čine ovaj rečnik veoma privlačnim za korisnika koji ima potrebu za osnovnim izrazima karakterističnim za neke svakodnevne situacije ili u početnim fazama učenja španskog jezika.

Ista izdavačka kuća, Vulkan izdavaštvo iz Beograda, objavila je Srpsko španski rečnik osnovnih reči i izraza sa izgovorom 2015. godine, autorki Aleksandre Golubović i Vesne Zorić. U pitanju je rečnik malog formata i modernog dizajna (izgledom podseća na mobilni telefon), rađen u boji, što ga dodatno čini atraktivnim. Iako u nazivu stoji „rečnik“, nije u pitanju klasično leksikografsko delo već pre svojevrstan sažeti priručnik, u kome će korisnici pronaći neke opšte izraze potrebne u različitim situacijama (putovanja, u hotelu, banci, pošti, restoranu, kupovini, itd.). U pitanju je, može se reći, „šablonski“ mini-priručnik, prethodno izrađen za engleski, francuski, italijanski i nemački jezik.

U Novom Sadu, izdavačka kuća Lingea objavila je 2017. godine Španski džepni rečnik (ne samo za početnike), malog formata i obima (31.000 reči), koji čini deo edicije autorskog kolektiva Lingea d.o.o., zajedno sa rečnicima srpskog i engleskog, nemačkog, francuskog, italijanskog, ruskog i drugih jezika. ${ }^{24}$ Iz Predgovora saznajemo da je rečnik sačinjen od reči savremenog španskog jezika, koje su u opštoj upotrebi Ż kako u učenju jezika, tako i u svakodnevnom životu i radu. Rečnik sadrži i neke učestale izraze iz književnog ali i govornog jezika. Posebno se naglašava da je rečnik zasnovan na relevantnim izvorima, koje čine reprezentativni jednojezični rečnici španskog, poput rečnika Španske kraljevske akademije, rečnika CLAVE, rečnika Diccionario de Salamanca i drugih, što je nesumnjivo dobra i pouzdana osnova za dvojezični rečnik. I u ovom rečniku izdvajamo upotrebu više korisnih informacija za pravilnu upotrebu reči: glose, oznake

\footnotetext{
${ }^{23} \mathrm{U}$ instrukcijama za korišćenje rečnika navode se i neke „praktične aktivnosti“ za upotrebu rečnika, koje treba da posluže memorisanju reči i izraza i bogaćenju osnovnog vokabulara.
}

${ }^{24}$ Rečnici su dostupni na https://recnici.lingea.rs/ 
za jezički stil, geografsku upotrebu i dr. Odgovarajući spisak skraćenica dat je na početku rečnika, dok se na kraju nalazi indeks nepravilnih glagola, s brojem strane na kojoj se nalazi svaki od njih, a date su i paradigme nepravilnih glagola, koji su u rečniku označeni zvezdicom. Kod nepravilnih glagola se, takođe, ukazuje na model promene, što korisnicima ovog leksikografskog dela značajno olakšava adekvatnu upotrebu glagolskih oblika. Rečnik prepoznaje značaj izraza, ustaljenih i terminoloških sintagmi, ali i ustaljenih formula, a uvodi ih znakom $>$ :

llevar (...) $\triangleright \sim$ la responsabilidad de alg biti odgovoran za šta; (puesto) imati na sebi; alg consigo uzeti šta sa sobom; llevarse bien con algn složiti se sa kim, biti dobar sa kim; (se) alg odneti koga/šta gde (na drugo mesto).

Ukoliko reč pripada dvema kategorijama (npr. pridev i imenica), onda se njihova značenja razdvajaju znakom ^:

abonado,-a prid. pretplaćen (novine itd.) $m$ pretplatnik (novina itd.); adulto,-a prid. odrastao, velik (odrasli itd.) $m$ odrasli).

Homonimi se u ovom rečniku tretiraju kao zasebne odrednice (npr. alto, predlog, redak, itd.). ${ }^{25}$ Rečnik beleži i nazive nekih država, planinskih venaca i naziva naroda i nacionalnosti, a uočava se i nekolicina skraćenica, kao na primer SAD, NATO / EE.UU., OTAN. Najzad, rečnik obiluje glosama odnosno propratnim informacijama, od kojih se posebno ističu one koje se odnose na domen upotrebe i valentnost, što nesumnjivo pozitivno utiče na kvalitet rečnika; na primer:

cargar* gl (conj pagar) 1 natovariti šta kamo (na kamion itd.), opteretiti šta (težinom) $\mathbf{2}$ napuniti (oružje) 3 napuniti (bateriju itd.), puniti (bateriju) 4 opteretiti koga čim, opterećivati (porezom itd.) $\mathbf{5}$ pripisati na dug šta $\mathbf{6}$ učitati (podatke) (...)

tući gl 1 koga pegar a algn, dar una paliza a algn 2 (o srcu) latir 3 šta golepar alg, dar golpes en alg 4 (šlag itd.) montar, batir

Na samom kraju rečnika, na poslednjoj strani, nalaze se osnovni i redni brojevi, nazivi za dane i mesece, delove dana, te nekoliko korisnih izraza.

Zavod za udžbenike iz Beograda objavio je seriju školskih dvojezičnih rečnika, među kojima se 2018. godine našao i Špansko-srpski / srpsko-španski rečnik za osnovnu školu, autorke Luize Valožić. Štampan

\footnotetext{
${ }^{25} \mathrm{Ne}$ ulazimo u kriterijume određivanja homonima.
} 
je ćiriličnim pismom u 3.000 primeraka. Kako se vidi iz predgovora, ovaj rečnik je namenjen đacima osnovne škole koji uče španski kao strani jezik, ali ga „mogu koristiti i svi oni koji uče španski jezik putem drugih vidova nastave ili samostalno" (str. IX). Špansko-srpski deo rečnika sadrži oko 3.900 odrednica, a 3.500 obuhvata srpsko-španski rečnik. U skladu s tipom korisnika kojima je rečnik namenjen, značenja su ilustrovana primerima, a dato je i sažeto uputstvo za korišćenje rečnika, koje uključuje i pojašnjenje upotrebljenih rečničkog metajezika, što je veoma važan segment svakog rečnika. Nakon uputstva data je španska abeceda $\mathrm{s}$ fonetskom transkripcijom španskih glasova, a potom i lista skraćenica. Rečnik je štampan u boji, čime je i vizuelno prilagođen tipu korisnika. Najzad, rečnik sadrži i nekoliko dodataka, i to: listu s nazivima zemalja i gradova sveta na španskom jeziku, nazive španskih pokrajina, njihovih glavnih gradova i stanovnika, tabelu sa osnovnim brojevima, a potom i špansko-srpski tematski vokabular (hrana, piće, voće, povrće, biljke, domaće životinje, divlje životinje, delovi tela, prostorije u kući i nameštaj). Na kraju izdanja je i spisak korišćenih rečnika.

\subsection{Višejezični rečnici koji uključuju španski i srpski jezik}

U jugoslovenskoj leksikografskoj fazi izrađena su 4 višejezična rečnika koja u naslovu imaju srpski / srpskohrvatski ili hrvatskosrpski jezik, a u postjugoslovenskoj fazi ima ih $11 .{ }^{26}$ Iako su neki od njih lokalizovani na srpski, odnosno postojeći rečnici su prošireni terminima u srpskom jeziku (npr. Internacionalni rečnik pozorišnih termina, Evropski rečnik, Rečnik EUROVOC itd.), ima i višejezičnika koji su autorski (npr. Višejezični rečnik voća, povrća i začina, Višejezični terminološki rečnik istorije umetnosti itd.). ${ }^{27}$

Posebno bismo izdvojili najnoviji od njih, Višejezični terminološki rečnik istorije umetnosti srpsko-francusko-italijansko-španski sa dvojezičnim glosarima (Beograd: Filozofski fakultet, Univerzitet u Beogradu, 2018), koji sadrži približno 30.000 odrednica. Autorke ovog

\footnotetext{
${ }^{26}$ Višejezični dendrološki rečnik Milorada Šijka ne sadrži nazive jezika u naslovu, ali se i španski jezik nalazi među njima, premda ne kod svih termina.

${ }^{27}$ Postoje publikacije nalik višejezičnim rečnicima (npr. Jezici sredozemnih zemalja (i engleski), Beograd: Yu marketing press - Verzal press, 1999. ili Rečnik i razgovornik / Vocabulario y frases cotidianas / Vocabulary and Everyday Phrase (srpski, španski, engleski) Beograd: YU Marketing Press, 2002, čiji je priređivač, u oba slučaja, Stanoje Jovanović, a prevoditeljka za španski jezik Nadežda Zarubica); međutim, nisu u pitanju višejezičnici već bazični jezički priručnici, koji sadrži tematski uređene osnovne reči i izraze, karakteristične za svakodnevne situacije.
} 
rečnika, Jasna Vidić, Danijela Đorović i Marina Nikolić, predaju pomenuta tri strana jezika na Filozofskom fakultetu u Beogradu. Istraživački pravci autorki usmereni su, pre svega, ka jeziku struke, metodici nastave stranih jezika, leksikografiji i prevođenju, a osim sopstvenih znanja i kompetencija unesenih u ovaj rečnik, koristile su i opšte, stručne, terminološke i enciklopedijske rečnike pomenutih jezika, zatim opšte dvojezične rečnike, kao i stručnu literaturu, što je rezultiralo bogatim i jasno utemljenim terminološkim rečnikom. Prema rečima autorki, „iako zamišljen kao terminološki, ovaj Rečnik razlikuje se od uobičajenog rečnika toga tipa po tome što je u odrednice uvršten i veći broj prideva i glagola, koji se, za razliku od imenica, tradicionalno ne smatraju terminima" (str. 9). Ovakav odabir odrednica opravdan je time što je rečnik namenjen, pre svega, studentima istorije umetnosti, kao pomoć u savladavanju stručne terminologije. Rečnik sadrži i uputstvo za korišćenje, kao i odgovarajući spisak skraćenica i korišćenih simbola, čime se olakšava adekvatna upotreba rečnika. Prema uvodnim rečima Saše Brajović, redovne profesorke na Odeljenju za istoriju umetnosti Filozofskog fakulteta, „ovaj rečnik je ne samo ozbiljna i dragocena pomoć već i putokaz kako istinski čitati, promišljati i razumeti svet kulture i umetnosti“" (str. 8).

\section{Zaključne napomene}

Pretraživanjem bibliotečkih fondova u potrazi za leksikografskim delima koja uključuju španski i srpski jezik, ustanovili smo, najpre, da su prvi rečnici ovih jezika objavljeni 60 -ih godina XX veka, kada se zvanični jezik na teritoriji bivše Jugoslavije nazivao srpskohrvatski ili hrvatskosrpski. Zatim, od 90-tih godina, u Republici Srbiji je objavljeno 20 dvojezičnih rečnika, različitog obima, formata i tipa (5 opštih /selektivnih/, 8 džepnih, 4 specijalizovana, 3 slikovna ili ilustrovana), dok se jedini elektronski rečnik, čiji zapis postoji u sistemu, iz 2007. godine, i dalje vodi da je u pripremi. Objavljeno je, takođe, 11 višejezičnika, gde se među jezicima nalaze i španski i srpski jezik, a koji pokrivaju različite oblasti.

Postojanje solidnog broja specijalizovanih, pre svega terminoloških, rečnika (dvojezičnih i višejezičnih) u odnosu na opšte mogao bi da ukazuje na veću potrebu za upravo ovom vrstom leksikografske građe, dok preštampavanje rečnika opšte namene može da se tumači kao indikator potrebe za rečnicima koji obuhvataju opšti leksički fond. Odsustvo obimnijih rečnika opšte namene moglo bi da se objasni i time da, s jedne strane, njihova izrada zahteva, osim odgovarajućih kompetencija, veoma mnogo vremena, napora i adekvatnu tehničku podršku, pri čemu 
leksikografski rad nije adekvatno vrednovan, a s druge time da prevodioci imaju visok nivo poznavanja kako jezika s kojeg prevode tako i maternjeg jezika, da se služe kvalitetnim i pouzdanim jednojezičnim rečnicima.

Budući da ne raspolažemo podacima o autorima rečnika, ne možemo biti sigurni da se uvek radi o hispanistima. Iz nedovoljno sistematizovane makro- i mikrostrukture u pojedinim rečnicima, kao i na osnovu činjenice da se neretko radi o dvojezičnim rečnicima adaptiranim za srpski i španski jezik, zaključujemo da autori i priređivači nisu formirani kao leksikografi, a iz uočenih jezičkih grešaka u nekima od njih zaključujemo da nisu ni filolozi-hispanisti.

Na kraju, možemo da zaključimo da srpska hispanistika i dalje stoji pred ogromnim leksikografskim izazovom - izradom obimnijeg španskosrpskog / srpsko-španskog rečnika opšte namene.

\section{BIBLIOGRAFIJA}

Ernandes Ernandes 2000: Humberto Hernández Hernández. «El diccionario en la enseñanza de E.L.E. (Diccionarios de español para extranjeros)». M. a Antonia Martín Zorraquino y Cristina Díez Pelegrín (Eds.), ¿Qué español enseñar? Norma y variación lingüísticas en la enseñanza del español a extranjeros. Actas del XI Congreso Internacional de ASELE, Zaragoza: Servicio de Publicaciones de la Universidad de Zaragoza, 93-103.

Kocjančič 2004: Polonca Kocjančič. "Acerca de la macroestructura y la microestructura en el diccionario bilingüe», Verba Hispanica, 12: 171-185.

Kostić-Tomović 2017: Jelena Kostić-Tomović. Savremena nemačka leksikografija. Nemački i srpsko-nemački rečnici u prvoj polovini 21. veka: tipovi, vrste informacija i upotreba. Beograd: FOKUS.

Pejović 2013: Andjelka Pejović. «Alcances y perspectivas del español en Serbia», Acta Hispanica, XVIII: 49-60.

Porto Dapena 2002: José-Álvaro Porto Dapena. Manual de técnica lexicográfica. Madrid: Arco Libros.

Radić-Dugonjić 2002: Милана Радић-Дугоњић. „Српски језички тип и преводна лексикографија“. Дескриптивна лексикографија стандардног језика и њене теоријске основе, Нови Сад: Матица српска, Београд: Институт за српски језик САНУ, 343-350.

Ruštaler 2005: Stefan Ruhstaller. «Consideraciones sobre los diccionarios monolingüe y bilingüe». M. a $^{-}$Auxiliadora Castillo Carballo et al. 
(Coords.), Las gramáticas y los diccionarios en la enseñanza del español como segunda lengua: deseo y realidad, Sevilla: Universidad de Sevilla, 86-93.

Soldatić 2011: Dalibor Soldatić. „Hispanistika u svetu i u Srbiji“. Dalibor Soldatić i Željko Donić, Svet hispanistike. Uvod u studije, Beograd: Zavod za udžbenike, 7-37.

Šipka 2006: Danko Šipka. Osnovi leksikologije i srodnih disciplina. Novi Sad: Matica srpska.

Zgusta 1991: Ladislav Zgusta. Priručnik leksikografije. (Prevod: Danko Šipka) Sarajevo: Svjetlost.

\section{DODATAK 1: Dvojezični rečnici koji uključuju španski i srpski/ srpskohrvatski jezik (hronološki, prema prvom izdanju)}

\section{Jugoslovenska faza}

1962: Grujić, Branislav. Džepni špansko-srpskohrvatski rečnik sa kratkom gramatikom španskog jezika. Beograd: Prosveta; Cetinje: Obod, 1962.

1965: Grujić, Branislav. Džepni srpskohrvatsko-španski rečnik. Beograd: Prosveta, Cetinje: Obod, 1965.

1971: Vinja, Vojmir; Ratibor Musanić. Španjolsko-hrvatskosrpski rječnik s osnovama španjolske gramatike i španjolskog trgovačkog dopisivanja. Zagreb: Školska knjiga, 1971. (XV+1132 strane)

1972: Vinja, Vinja; Kožljan, Rudolf. Langenscheidtov univerzalni rječnik. Španjolsko-hrvatskosrpski, hrvatskosrpsko-španjolski. Zagreb: Mladost, 1972.

1977: Strugar, Novak. Leksikon društveno-političke i samoupravne terminologije: srpskohrvatski-španski. Beograd: APS, 1977.

Postjugoslovenska faza:

dvojezični špansko-srpski / srpsko-španski rečnici

...1994: Grujić, Branislav. Džepni špansko-srpski rečnik sa kratkom gramatikom španskog jezika. Cetinje: Obod, 1994.

...1999: Grujić, Branislav. Džepni srpsko-španski rečnik. Cetinje: Obod, Beograd: Draganić, 1999.

1995: Stojanović, Zoja; Ivana Stojanović. Džepni srpsko - španski rečnik. Beograd: Pirg: Svjetlost - B, 1995. 
1997: Vegas de Spalajković, Carmen. Business rečnik špansko-srpski: srpsko-španski. Beograd: Ž. Albulj, 1997.

1998: Boričić, Jasmina. Špansko-srpski i srpsko španski rečnik (sa osnovama španske gramatike). Zemun: JRJ, 1998.

2001: Grujić, Branislav. Nuevo diccionario estándar español-serbio serbioespañol / Novi standardni rečnik špansko-srpski srpsko-španski. Nikšić: Jasen, 2001.

2002: Vajs, Bruno; Zoran Davidović. Španski slikovni rečnik. Beograd: Alnari, Ateneum, 2002.

2003: Špansko-srpski srpsko-španski didaktički rečnik / Diccionario didáctico español-serbio serbio-español. Beograd: Foto futura, 2003.

2004: Panžić, Marijana; Biljana Kovačević. Špansko-srpski i srpsko-španski rečnik. Beograd: Duška, 2004. (ćir.)

2005: Tošić, Dragana. Srpsko-španski rečnik pravnih i poslovnih termina / Diccionario de términos jurídicos y de negocios serbio-español. Beograd: Službeni glasnik, 2005.

2005: Nikolić, Vojislav. Špansko-srpski / srpsko-španski rečnik. Beograd: Jasen, 2005.

2006: Romčević, Biljana. Ilustrovani rečnik španskog jezika. Beograd: Teatar Za; Novi Sad: Liber, 2006. (ćir.)

2006: Stojanović, Milutin. Rečnik fraza i opštih izraza: srpsko-španski: 55.000 terminoloških jedinica. Beograd: Građevinska knjiga, 2006.

2006: Vegas de Spalajković, Carmen. Rečnik idioma i fraza: špansko-srpski srpsko-španski. Beograd: Megatrend univerzitet, 2006.

2013: Nikitović, Veljko. Srpsko-španski / špansko-srpski rečnik sa gramatikom. Beograd: Book, 2013.

2014: Džepni rečni srpsko-španski. Beograd: Jasen, 2014. (ćir.) (urednik Milomir Kragović)

2014: Dvojezični slikovni rečnik (špansko-srpski). Beograd: Vulkan izdavaštvo, 2014. (urednik Nenad Atanasković; prevod Dubravka Trišić i Svetlana Babović)

2015: Golubović, Aleksandra; Vesna Zorić. Srpsko španski rečnik osnovnih reči i izraza sa izgovorom. Beograd: Vulkan izdavaštvo, 2015.

2017: Španski džepni rečnik (ne samo za početnike). Novi Sad: Lingea, 2017.

2018: Valožić, Luiza. Špansko-srpski / srpsko-španski rečnik za osnovnu školu. Beograd: Zavod za udžbenike, 2018. (ćir.) 


\section{DODATAK 2: Višejezični rečnici koji uključuju španski i srpski / srpskohrvatski jezik (hronološki, prema prvom izdanju)}

Jugoslovenska faza

1969: Simeon, Rikard and Vlatko Pavletić. Enciklopedijski rječnik lingvističkih naziva na 8 jezika: hrvatsko-srpski, latinski, ruski, njemački engleski, francuski, talijanski, španjolski. I: A-0. 1. izd. Zagreb: Matica hrvatska, 1969.

1969: Simeon, Rikard and Vlatko Pavletić. Enciklopedijski rječnik lingvističkih naziva na 8 jezika: hrvatsko-srpski, latinski, ruski, njemački engleski, francuski, talijanski, španjolski. II: P-Ž. 1. izd. Zagreb: Matica hrvatska, 1969.

1987: Ladan, Tomislav. Osmojezični enciklopedijski rječnik: hrvatski ili srpski, ruski, engleski, njemački, francuski, talijanski, španjolski, latinski. Vol. 1: A - E. Zagreb: Jugoslavenski leksikografski zavod Miroslav Krleža, 1987.

1991: Višejezični pravno-ekonomski rečnik: srpskohrvatski, slovenački, makedonski, ruski, engleski, nemački, francuski, italijanski i španski: 768 termina i izraza iz Zakona o stranim ulaganjima i Zakona o preduzećima. Beograd: Udruženje naučnih i stručnih prevodilaca Srbije, 1991.

\section{Postjugoslovenska faza}

1993: Opšti leksikon železničkih stručnih izraza: francuski, nemački, engleski, italijanski, španski, srpski. Beograd: Zavod za novinskoizdavačku i propagandnu delatnost JŽ, 1993. (4. izd.)

1994: Čobić, Timotej. Višejezični rečnik voća, povrća i začina: srpskolatinsko-englesko-francusko-nemačko-špansko-ruski, Beograd: Prosveta, 1994.

1996: Međunarodni elektrotehnički IEC rečnik sa terminima na srpskom jeziku: elektroenergetika, elektronika i telekomunikacije. Knj. 1 (engleski, francuski, ruski, nemački, španski, italijanski, holandski, poljski, švedski, srpski). Beograd: Savezni zavod za standardizaciju, 1996.

1996: Rečnik železničkih stručnih izraza: francusko-nemačko-engleskoitalijansko-špansko-srpski. Beograd: Želnid, 1996. (glavni prevodilac: Gvozden Sredić; prevodioci: Snežana Petrović et al.) 
1997: Rej, Kenet; Ričard Sautern. Internacionalni rečnik pozorišnih termina: srpski, engleski, francuski, nemački, italijanski, španski, holandski, švedski. Beograd: Gea, 1997.

1998: Gurso, Anri. Evropski rečnik (srpski, engleski, nemački, francuski, italijanski, španski). Beograd: Narodna knjiga-Alfa, 1998.

2000: Šijak, Milorad. Višejezični dendrološki rečnik. Vocabularium dendrologicum multilinguum, Beograd : Šumarski fakultet, 2000.

2003: Fudbalski rečnik / Footbal Dictionary / Dictionnaire du football / Diccionario del fútbol: srpsko-englesko-francusko-španski. Beograd: A. Mihajlović, 2003. (Urednik: Aleksandar Mihajlović; prevodilac: Đorđe Dimitrijević)

2004: Maletin, Stevan; Timotej Čobić; Vladimir Kunc; Milanko Bekvalac. Višejezički rečnik ribarstva (englesko-francusko-nemačko-španskosrpski) / Multilingual Dictionary of Fishery (English-French-GermanSpanish-Serbian) / Dictionnaire polyglote des pêches (anglaisfrançais-allemand-espagnol-serbe) / Mehrsparachiges Wörterbuch der Fischerei (Englisch-Französisch-Deutsch-Spanisch-Serbisch) / Diccionario poligloto de la pesca (inglés-francés-alemán-españolserbio). Novi Sad: Poljoprivredni fakultet, 2004.

2006: Rečnik EUROVOC: višejezično izdanje: srpski, engleski, francuski, nemački, italijanski, španski. Beograd: Institut za međunarodnu politiku i privredu, 2006. (ćir.)

2018: Vidić, Jasna; Danijela Đorović; Marina Nikolić. Višejezični terminološki rečnik istorije umetnosti srpsko-francusko-italijanskošpanski sa dvojezičnim glosarima. Beograd: Filozofski fakultet, Univerzitet u Beogradu, 2018. (ćir.) 


\title{
ON DICTIONARIES THAT INCLUDE
} SPANISH AND SERBIAN LANGUAGE

\begin{abstract}
Summary
The paper provides an overview of dictionaries that include Spanish and Serbian Language, published on the territory of the former Yugoslavia and in the Republic of Serbia, until 2019. The first dictionaries which include the mentioned languages date from the 1960s, and since the 1990s, 20 bilingual dictionaries and 11 multilingual dictionaries more have been published in the Republic of Serbia. A solid number of specialized, primarily terminological, dictionaries in relation to general ones could indicate a greater need for this type of lexicographic publications, while the reprinting of general purpose dictionaries can be interpreted as an indicator of the need for dictionaries that include general lexical fund. The absence of extensive general purpose dictionaries could be explained by the fact that, on the one hand, their development requires, in addition to appropriate competencies, a lot of time, effort and adequate technical support, where lexicographic work is not adequately evaluated, and on the other, the translators have a high level of knowledge of both the language from which they translate and their mother tongue, so they prefer using quality and reliable monolingual dictionaries.
\end{abstract}

Keywords: lexicography, dictionaries, bilingual dictionaries, multilingual dictionaries, Spanish Language, Serbian Language. 